\title{
Aristotle's Syllogistic Model of Knowledge and the Biological Sciences: Demonstrating Natural Processes
}

\author{
Mariska Leunissen
}

In the Posterior Analytics (APo), Aristotle defines scientific knowledge as knowledge of the reason why. Knowing why something is the case amounts to being able to provide a scientific demonstration (apodeixis), which consists in a valid syllogistic argument in the mode Barbara. Such demonstrations typically deduce the necessity of an attribute belonging per se to a certain subject through a middle term that picks out the cause of that necessary relationship. Aristotle often illustrates this syllogistic model of knowledge with examples drawn from mathematics, which is taken to be the paradigmatic demonstrative science (cf. APo I 14, 79a1821), presumably because the per se attributes of mathematical figures (e.g., triangles having angles equal to two rights) can be shown to hold of those figures necessarily and always.

Notoriously, this is not the only model of demonstration at work in Aristotle's natural treatises (nor in the Aristotelian corpus as a whole, for that matter). ${ }^{1}$ In his methodological introduction to the study of living beings in the Parts of Animals (PA) I 1, Aristotle argues that sublunary natural phenomena - which involve change and hold only for the most part - can be demonstrated scientifically. However, they require a different model of demonstration that is special to the natural sciences and that is perhaps absent from the Posterior Analytics (see especially

1 See Lloyd (1996), 7-37. 
PA I 1, 639a12-15; 640a1-9; 640a33-b3; 642a32-b2). ${ }^{2}$ In this model, the necessity of the relationship between the attribute and the subject is conditional, rather than unqualified, and the causal nature of the demonstration is strictly teleological. In addition, unlike the geometric-style model of demonstration set out in the Posterior Analytics, which seems particularly fit for dealing with eternal and stable matters of fact, the natural science model of demonstration pertains to processes or developments - that is, to attributes coming to hold of certain animals or their parts as the result of the operation of teleology or material necessity.

A third model of demonstration - if we can indeed still speak of a model - is provided by the many different, often very loosely formulated, patterns of explanation in Aristotle's biology. In his biological works, Aristotle states explicitly that he aims at generating demonstrations of some sort, ${ }^{3}$ but he only rarely identifies his explanations as demonstrations and never formalizes any of them into syllogistic form. However, in line with the model of demonstration introduced in Parts of Animals Book I, many of the actual explanations provided are teleological in nature and pertain to the coming to be, rather than to the presence of features. For instance, the program of Aristotle's Generation of Animals $(G A)$ is explicitly introduced as being about specifying the causes of the coming into being of living organisms (see especially GA I 1, 715a1-18 and GA II 1, 731b22-3) and explains, among others, the teleological process of embryogenesis. Even the Parts of Animals, in which Aristotle claims to take the being of biological kinds as the starting point of explanation (see in particular PA I 1, 640a10-33), contains a significant number of the so called 'double-barreled' explanations. These explanations distinguish explicitly between the material-efficient causes for the coming into being of parts and their differentiations on the one hand, and the final causes for their presence on the other hand. ${ }^{4}$

This plurality of models of demonstration, combined with the discrepancy between the focus on demonstrating eternal matter of facts in

2 On the differences and especially the similarities between demonstrations in the natural sciences and geometric demonstrations, see Gotthelf (1987), 197-8 and Lennox (2001b), 128-31.

3 See especially HA I 6, 491a7-13; PA IV 10, 689a9-13; GA II 6, 742b23-36; II 8; and IV 3, 769a14-25.

4 See e.g., Aristotle's explanation of horns in PA III 2, 663b21-35 and of the omentum in PA IV 3, 677b22-32. This distinction is also recognized in $P h$ II 8, 199a7-8 and GA V I 1, 778a30-b12; cf. Gotthelf (1987), 237-42. 
the Posterior Analytics and on demonstrating features that come to be in the biological treatises, has led some scholars to believe that Aristotle is a methodological pluralist regarding demonstration, whose theory and practice cannot be reconciled with each other. ${ }^{5} \mathrm{My}$ aim in this paper is to soften this picture by showing that, even though the main concern of the Posterior Analytics is to offer geometric-style demonstrations of 'being' (i.e., of why certain attributes hold always and of necessity of certain subjects), the Posterior Analytics also offers an account of how to incorporate time and change into the syllogistic structure of demonstration. In this way, the Posterior Analytics can be read as preparing us for the natural science model of demonstration. Aristotle may not have a monolithic and unified theory of demonstration, but there are also no radical breaks between Aristotle's 'original' model of demonstration in the Posterior Analytics and the ones employed in the biological works, in part because - as I shall argue - that original model itself is more flexible and complex than has traditionally been acknowledged. ${ }^{6}$

My argument consists of two parts. In section one I discuss a selection of texts especially from Book I of the Posterior Analytics, which shows that Aristotle from the outset assumes that there are demonstrations of processes as well as of timeless states of affairs and that he realizes that such demonstrations of processes often require modifications from the geometric-style model of demonstrations of being. In sections two and three I focus on Aristotle's most informative discussion of demonstrations of processes, which takes place in APo II 12, and show how this model converts to and guides Aristotle's theory and practice of demonstration in the biological sciences.

5 This position is defended most rigorously by Lloyd (1996), 7-37; see especially 5; 28 ('... and he certainly makes no comment here whatsoever on the question of whether - with those things that come to be - there is demonstration of the type he has exemplified from geometry.') and 32.

6 This project is thus in many ways indebted to and a continuation of the work done by scholars such as Balme (1987); Bolton (1987; 1997); Charles (1997; 1999); Detel (1997; 1999); Gotthelf (1987; 1997); Lennox (2001a; 2001b) and Pellegrin (1986), all of whom emphasize the similarities and continuities between Aristotle's theory and practice in the sciences. 


\section{Demonstrating processes: some first sketches in the Posterior Analytics}

It is commonly assumed ${ }^{7}$ that Aristotle modeled his syllogistic model of demonstration in the Posterior Analytics on the format and methods of proof that were being used by the mathematicians of his time, and this perhaps explains why the model is particularly well-suited for demonstrations of timeless (mathematical) matters of fact. The influence and importance of the mathematical model is especially clear in the first book of the Posterior Analytics, which draws heavily from mathematical examples (a stock example is 'triangles having angles equal to two rights': APo I 1, 71a19-22; passim). Aristotle also provides some examples from the natural or biological realm, but they too pertain for the most part to attributes that hold always and necessarily of the subjects of which they are predicated (e.g., animal holding of human being: APo I 4, 73a30-1; I 11, 77a15-19). However, even within the first book, Aristotle occasionally throws in an example of a process (e.g., goal-directed action in APo I 24, 85b30-5; psychological change in APo I 29, 87b8-13; and the screening of the moon by the earth in APo I 31, 87b38-8a5), and, more importantly, lays out some distinctions that seem to make room for the accommodation of processes within the syllogistic structure of demonstrations.

Book I contains three discussions that pertain in particular to demonstrations of processes. The first occurs in APo I 4, where Aristotle defines four types of per se relations between attribute and subject. The first three types involve only matter of facts, but the fourth explicitly appeals to processes, that is, to attributes coming to hold of a certain subject ( $A$ Po I 4, 73b10-16): ${ }^{8}$

In yet another way [we say that] something holds of each thing per se when it holds because of itself (di' hauto), and when it does not hold because of itself [we say that it] holds incidentally. For instance, if there was lightning while somebody walked (ei badizontos êstrapse), [we say that] it holds incidentally: for there was no lightning because of the walking, but, as we say, it just happened. But if something holds because of itself, [we say that it holds] per se, such as if something died

7 See e.g., Barnes (1993), xx; Lennox (2001a), 93-4; and Mendell (2004).

8 All translations are mine, unless indicated otherwise. 
while being sacrificed (ei ti sfattomenon apethane), and on account of the sacrifice, because of the being sacrificed, and not because it just happened that what was being sacrificed died.

The predicative relation exemplified in this passage is not an essential one, but rather a causal one that involves an attribute coming to hold of a certain subject due to the operation of an external efficient cause: 'died' comes to hold of a certain animal, because that animal is being (i.e., 'in the process of being') sacrificed. In addition, the predicative relation in this fourth type of per se is not always true in the way that triangles always have angles equal to two rights. Rather, the predicative relation only obtains whenever the external efficient cause obtains: the predicative relation thus seems to hold only for the most part. ${ }^{9}$

Next, in APo I 8, Aristotle distinguishes demonstrations of eternals from demonstrations of perishables. He explains that the latter only hold when the items picked out by the terms in the premises hold (APo I 8, 75b21-30) and that therefore our understanding of them is not simple, but involves knowledge of the 'when and how' (APo I 8, 75b26: pote kai pôs). He then singles out demonstrations of 'things that come about often' (APo I 8, 75b33: hai de tôn pollakis ginomenôn), such as an eclipse of the moon, and claims that the latter 'hold always to the extent that [eclipses] are such, ${ }^{10}$ but to the extent that they do not hold always, they are particular' (APo I 8, 75b34-35). According to this chapter, there are demonstrations of natural processes that come to be often, even if their epistemological status is different from demonstrations of eternals.

And finally, in APo I 30, Aristotle claims explicitly that there are no demonstrations of what happens by chance, but that there are both demonstrations that are concerned with items that are necessary and with processes that occur for the most part (APo I 30, 87b19-27; b20-1: hê apodeixis thaterou toutôn).

This overview is necessarily perfunctory, but it shows that even within the first book of the Posterior Analytics Aristotle distinguishes between two models of demonstration. The predominant model pertains to things that are eternal and necessary, is exemplified by geometrical

9 See Ferejohn (1991), 117-23.

10 With Barnes (1993), 134 I follow the text emendation proposed by Verdenius (1981), 347 and read toiaide instead of toioude in APo I 8, 75b34. 
examples, and matches the description of demonstration in the theoretical sciences in PA I 1, 640a1-9 (and Ph II 9, 200a15-22).

The second model, on the contrary, pertains to things that come to be and that hold for the most part, and is illustrated by natural processes and goal-directed actions. However, it is not until Book II that Aristotle offers us a specification of the syllogistic features of demonstrations of developments. The main problem - of how to incorporate change and time into the syllogistic structure of demonstrations - is first raised in APo II 11 and subsequently receives a full discussion in APo II 12.

In APo II 11 Aristotle introduces his theory of four types of causal explanation into the syllogistic framework of scientific demonstration: all four types of explanations are brought out through the middle term, which picks out the cause of why some attribute belongs to a certain subject. The details of Aristotle's account of the syllogistic structure of different types of demonstration in this chapter remain fairly obscure, ${ }^{11}$ but it is in the examples Aristotle provides in APo II 11, 94a27-b23 that the problem of how to incorporate processes and change into demonstrations first becomes evident.

Aristotle offers three examples in this chapter. He first gives a mathematical example to illustrate demonstrations of a material explanation (APo II 11, 94a27-35), which - at least structurally speaking — presents a fairly standard case of a demonstration of a timeless state of affairs. However, the next two examples presented in APo II 11 explicitly involve change. ${ }^{12}$ In the 'historical' example illustrating demonstrations of efficient explanation in APo II 11, 94a36-b8 Aristotle picks out the fact that the Athenians were the first to attack as the cause of why [later] the Persian war came upon them. ${ }^{13}$ The third example in APo II 11, 94b8-26 pertains to teleological explanation and draws from the realm of human activity. There the explanandum (walking after dinner) is revealed to

11 I present a possible interpretation in Leunissen (2007).

12 Cf. the examples Aristotle provides of things that are both for the sake of something and of necessity at the end of the chapter (APo II 11, 94b28-36): Aristotle suggests again that there are demonstrations both of what is and of what comes to be (APo II 11, 94b31-2: ar' oun ei einai endechetai, kai ginesthai endechetai).

13 Explanandum: Why did the Persian war come upon the Athenians? [Why A of C?] $\mathrm{A}=$ war; $\mathrm{B}=$ being the first to attack (aition = efficient cause) $\mathrm{C}=$ Athenians; $\mathrm{AaC}$ because of $B$ : being warred upon holds of the Athenians because of being the first to attack. 
take place for the sake of its expected (later) end-result and final cause (health). ${ }^{14}$ It is true that these latter two examples hardly look like scientific demonstrations at all, ${ }^{15}$ but presumably Aristotle is less concerned with the details of his examples than with the larger patterns that they are meant to illustrate in - for his contemporary audience - easy and intuitive ways.

That the - correct - incorporation of the temporal relations between the states of affairs picked out in these two demonstrations is important to Aristotle is clear from a short comment he makes at the end of the section dealing with the examples (APo II 11, 94b23-6):

Here the processes occur in the opposite order (anapalin) from the cases where the causes are according to motion. For in the latter the middle term must come to be first, while here $\mathrm{C}$, the ultimate term, [must come to be first] and last the for the sake of which.

In this passage, Aristotle contrasts the order of causation in demonstrations of efficient causal explanations with those of teleological explanations. The middle term in the example of efficient explanation (i.e., being the first to attack) picks out an event that later initiated the war against the Athenians. In other words, the predicative relation picked out in the conclusion of this efficient demonstration comes about later as a result of an action that was performed earlier by the subject; the explanatory efficient cause thus precedes the explanandum in time. ${ }^{16}$

However, in the example of teleological explanation, the action picked out by the subject term (i.e., walking after dinner, which is the explanandum) occurs first; the final cause, health, which is that for the sake of which walking takes place, comes about last. In other words, the state of affairs picked out as the final cause of the explanandum comes about as the end-result of the process of walking, which is an efficient cause that makes the food not floating on the surface of the stomach (where walking and making the food not float are simultane-

14 Explanandum: Why does he walk? [Why C?] For the sake of health. Why does health hold of walking? [Why A of C?] A = being healthy; B = food not floating (aition = material cause); $\mathrm{C}$ = walking after dinner; $\mathrm{AaC}$ because of $\mathrm{B}$ : being healthy holds of walking after dinner because walking makes the food not floating, and having the food not floating is what being healthy is in this context.

15 See Barnes (1993), 228-9.

16 Schematically, the timeline is as follows: $\mathrm{B}(\mathrm{aC})_{t 1} \rightarrow \mathrm{A}(\mathrm{aC})_{t 2}$. 
ous processes), and having the food not floating is a form of health (the condition of having the food not floating and of being healthy come to be simultaneously in time). Whereas walking thus is for the sake of health, health comes about as soon as the process of walking has made the food no longer float on the surface of the stomach. ${ }^{17}$

Aristotle does not explain why this difference between the temporal relations picked out in these two demonstrations is important, nor do we learn anything about the necessity of the premises involved in demonstrations of processes. The answers to these questions follow in the next chapter, to which I shall turn in the sections below.

\section{Demonstrations of simultaneous processes in $A P o$ II 12 and GA V}

Aristotle does not provide a separate introduction to APo II $12 .{ }^{18}$ The discussion of demonstrations of processes seems to follow naturally from his discussion of the implementation of the four causes into the syllogistic structure of demonstrations and the subsequent account of the role of necessity, teleology, and chance in natural processes at the end of $A P O$ II 11. His main concern in this chapter is to lay out the temporal properties of the terms picked out in demonstrations of processes: the examples all pertain to cases where the predication of an attribute to a certain subject involves a development or change, which may or may not separate cause (picked out by B) and what is caused (represented by A's coming to hold of C, or - what I here somewhat anachronistically call - the 'effect') in continuous time. Such demonstrations of processes are formally the same as demonstrations of being, except that the terms in the former get tensed (I return to this below).

17 Here, the timeline is: $\left(\mathrm{C}=\mathrm{B}_{\text {making }}\right)_{\mathrm{t} 1} \rightarrow \mathrm{A}(\mathrm{aC})_{\mathrm{t} 2}$, where $\mathrm{B}_{\text {having }}={ }_{\text {def. }}$ A. The example is difficult to reconstruct, in part because Aristotle appears to change the definitions of the terms; see Leunissen (2007), 161. For the timeline, cf. Ph II 6, 197b23-5: 'For instance, walking is for the sake of evacuating of the bowels; if this does not come to be for the person who walked (ei de mê egeneto badisanti), we say that the walking was in vain and that the walk was in vain.'

18 My discussion of APo II 12 is greatly indebted to Kupreeva (forthcoming), who offers an excellent analysis of the concepts of necessity and continuity in this chapter and suggests the relevance of Aristotle's treatment of demonstrations of processes in APo II 12 for his theory of demonstration in PA I. 
Aristotle analyzes three scenarios of the relationship between cause and 'effect':

1) A's coming to hold of $C$ and the coming to be of $B$ occur at the same time such that cause and effect occur simultaneously (APo II 12, 95a10-24);

2) A's coming to hold of $C$ and the coming to be of B occur not at the same time, but cause and effect are 'of the same type' (APo II 12, 95a24-5b1 and APo II 12, 95b13-37).

3) A's coming to hold of $C$ and the coming to be of B occur not at the same time, but cause and effect follow each other in a continuous circle (APo II 12, 95b38-6a7).

The analysis of the second scenario includes a brief investigation of the concept of the continuous (APo II 12, 95b1-12); the analysis of the third scenario is followed by an excursus on the nature of the predication of things that come to be for the most part, rather than universally (APo II 12, 96a8-19). In the sections below, I shall limit my interpretation to the first two models of demonstration and link them to Aristotle's theory and practice in the biological works. The third model, in which cause and effect follow each other in a continuous circle (such as in the evaporation-cycle), and which possibly forms the basis for Aristotle's treatment of the eternal cycle of animal generation in On Generation and Corruption (GC) II 9-11, falls outside the scope of this paper. ${ }^{19}$

Let me start by giving an account of the first model of demonstrations of processes. Aristotle starts his analysis of demonstrations of what later (i.e., in APo II 12, 95a21-22) turn out to be demonstrations of simultaneous processes by pointing out that the cause picked out by the middle term is the same both in demonstrations of things that come to be and of things that are (APo II 12, 95a10-14).

Demonstrations of things that come to be are thus causally and logically similar to demonstrations of things that are, but there is one important difference: while in demonstrations of being the predication is not subject to developments over time and holds of necessity, in demonstrations of coming to be the predication does involve a development

19 For an excellent discussion of these texts, I refer to Kupreeva (forthcoming) and Lennox (1985). 
over time, which means that the terms get tensed. Aristotle's examples of an eclipse and ice make clear what he has in mind (APo II 12, 95a1421):

For instance, because of what did an eclipse come about (dia ti gegonen ekleipsis)? Because the earth came (gegonen) in the middle; and it is coming (ginetai) about because [the earth] is coming (ginetai) [in the middle], and it will come about (estai) because [the earth] will come (estai) in the middle, and there is (esti) [an eclipse] because [the earth] is (esti) [in the middle]. What is ice? Assume that it is solidified water. Let water be C, solidified A, and the explanatory middle term is B, complete cessation of heat. Ice comes to be (ginetai) if $\mathrm{B}$ comes to be (ginomenou tou B), it came to be (gegenêtai) if B came to be (gegenêmenou), and it will come to be (estai) if B will (esomenou).

The point Aristotle is trying to make here is that in those cases where cause and effect occur simultaneously, the tense of the major term (and therefore the 'ontological condition' of the state of affairs picked out by the major term) has to correspond to the tense of the middle term. This is because in these cases the processes picked out by the major term (i.e., eclipsing or solidification) come to hold of a certain subject at the same time as and to the same degree as the states of affairs picked out by the middle term come to be (APo II 12, 95a22-4): 'Eclipsing' of the moon happens simultaneously with the earth moving in the middle between the sun and the moon; solidification of water (or: the coming to be of ice) happens simultaneously with the complete cessation of heat. ${ }^{20}$

Interestingly, both the examples Aristotle offers in this section involve natural phenomena, but they are of the kind that happen entirely of material necessity and not for the sake of something. In addition, the attributes 'being eclipsed' and 'solidified' come to hold of their subjects 'moon' respectively 'water', not in virtue of themselves, but in virtue of being acted upon by an external efficient cause (note that the examples are not unlike the 'dying in virtue of being sacrificed' example used in $A P o$ I 4 for the illustration of the causal notion of per se): the position of

\footnotetext{
20 Schematically, we get: $\mathrm{A}=$ eclipse ['eclipsing'] $\quad \mathrm{A}=$ solidified 
the earth determines whether or not and to what extent 'being eclipsed' holds of the moon, and the external heat determines whether or not and to what extent solidification holds of water.

In the biological works, explanations that pick out external efficient causes that occur simultaneously with their effects are relatively rare (they may be more common in the Meteorology, which is concerned with the changes that affect the four sublunary elements) ${ }_{1}^{21}$ but they occur frequently in Generation of Animals Book V.2. In this book, Aristotle discusses a very specific group of attributes or pathêmata 'by which the parts of animals differ', such as differences in eye-color, hair-structure, and pitch of voice, that all come to be due to changes occurring during the development of the animal after its birth (GA V 1, 778a16-28). In many cases, those changes are due to the material nature of the animal itself, ${ }^{23}$ but sometimes they occur under the influence of the operation of external material-efficient causes, such as the (changing) temperature of the animal's environment ${ }^{24}$ or diseases. ${ }^{25}$ When the natural heat of the animal is affected, either from the outside through changes in the environment, or from the inside through a disease, some of its attributes undergo notable changes. And as Aristotle points out, those changes correlate and happen simultaneously with the changes in heat. For instance, what causes hair to turn grey in human beings (besides old age) is the influence of disease: disease is a (temporary) deficiency in natural heat, which makes the body go cold and renders it incapable of concocting the moisture in hair, and this causes the hair to 'mould' and turn white. Once the disease is gone, however, and the internal heat restored, the hair may change back into its normal color (GA V 4, 784b26-32): as Aristotle points out, the attributes change together with (GA V 4, 784b31: ta pathê summetaballousin) the changes in the level of bodily heat, which in its turn is determined by the presence or absence

21 See, e.g., the explanations of snow and hoar-frost in Mete I 11, 347b23-4; the explanation of the moistness of the earth as correlating with (metaballousin) the coming into being and perishing of rivers in Mete I 14, 351a19-21; and the explanation of earthquakes in Mete II 8, 365b21-3 and 368a7-8.

22 For an overall interpretation of $G A \mathrm{~V}$, see Leunissen \& Gotthelf (in preparation).

23 For examples, see GA V 1, 779b2; V 3, 784a4-5; V 6, 785b16-6a2 and V 6, 786a2-4.

24 For examples, see GA V 2, 781a33-4; V 3, 782b32-3a1; V 3, 783a11-32; V 3, 784a12-20; V 6, 786a30-4; and V 7, 788a16-20.

25 See e.g., GA V 1, 780a14-21 and V 4, 784a25-30. 
of disease. Similarly, our hearing deteriorates at the same time as we yawn or breath out, because the organ of hearing and the organ concerned with breathing are spatially connected, and the organ of hearing 'is being shaken and moved at the same time as the [other] organ moves the air' (GA V 2, 781a30-4; 32-3: seiesthai kai kineisthai hama kinountos tou organou to neuma).

Unusual as many of these explanations in Generation of Animals $\mathrm{V}$ may be, they seem perfectly in line and consistent with the first model of demonstrations of processes outlined in APo II 12. This is evidenced by Aristotle's concern in Generation of Animals V with explicating not just the causes of the coming to be of certain attributes, but also with pointing out their simultaneous occurrence with the occurrence of their causes (cf. Aristotle's frequent use of the verb summetaballô in these contexts). ${ }^{26}$ This model, then, works well for the explanation of certain phenomena that are due to material-efficient causation (i.e., where the affection that needs to be explained occurs simultaneously with the operation of the efficient cause on the subject), but it may not work as well for the explanation of teleological phenomena. Teleological processes typically involve the realization of a potential for form, ${ }^{27}$ and the end that constitutes the final cause of that process comes to be last: cause (i.e., the presence of a potential for form in some subject) and effect (i.e., the realization of that form in that subject) do not occur simultaneously in teleological processes, but are separated in time. For a model that fits teleological explanation better, and which was possibly the template for the account of demonstration in Parts of Animals I, we need to turn to Aristotle's discussion of the second scenario in the Posterior Analytics, described in APo II 12, 95a24-95b1 and 95b13-b37.

\section{Demonstrations of same-type processes in APo II 12, PA I-II, and GA II}

The second scenario of demonstration of processes Aristotle discusses involves cases where cause and effect do not occur simultaneously, but occur or come to be at different instances in a continuous time-se-

27 I here follow the interpretation of Aristotle's teleology as introduced by Gotthelf (1976) and (1987). 
quence. Aristotle asks whether we can say that one process is the cause of another. The answer appears to be yes (APo II 12, 95a25: hôsper dokei hêmin): it is possible to explain something that is coming to be by reference to something else that was coming to be earlier, and similarly for processes taking place in the future or in the past. In the subsequent elucidation of his answer, Aristotle makes the following three claims about the syllogistic structure of such demonstrations:

First, in cases where cause and effect are separated in time and where the two follow each other linearly (i.e., the cause occurs first, then the effect) rather than in a continuous cycle, 'the syllogism starts from what has happened later' (APo II 12, 95a27-8). This means that the inferences involved in the construction of demonstrations of linear processes must start from the effects and work back to their necessary antecedent causes. ${ }^{28}$ The endpoint of the causal process is thus the starting point of the syllogism. As Aristotle points out, there can be no inference in the other direction, which would be from what is earlier to what is later (APo II $12,95 \mathrm{a} 30-1)$. The reason is that, regardless of what the exact nature of time is, given a particular sequence of processes that take place in time there will always be a moment when the cause has occurred but not yet its effect, such that at that intermediate time inferences from cause to effect will be false (APo II 12, 95a31-5; 95a39-b1). For the syllogistic model of demonstrations of such phenomena this analysis entails that the cause picked out by the middle term must have occurred chronologically earlier than the states of affairs picked out in the conclusion that is to be demonstrated. (As Aristotle points out in Ph II 9, 200a1522 , demonstrations of sublunary, linear natural phenomena are in this respect dissimilar to demonstrations of mathematical objects which do not involve changes over time: although the inferences in both domains are one-directional, in mathematics one needs to start with the prior and work towards the posterior in order for the inference to be valid. $)^{29}$

Second, Aristotle explains that in these cases the middle term, which picks out the cause, must be 'homogonos' with (i.e., 'of the same type as'; see APo II 12, 95a36-8) its effect, which means that the middle term must express the same tense as is expressed in the extreme terms, specifically as is expressed in the major term. We can thus only provide demonstrations of a sequence of processes in which all processes are of

Cf. Wieland (1972), 232.

29 For this interpretation, cf. Gotthelf (1987), 197-8. 
the same type, i.e., they must all be either past, future, or present happenings. There are no inferences from past to future processes, because there is no middle term that can be of the same type as both extremes (APo II 12, 95a38-9).

Third, Aristotle states that the middle term and the major term of demonstrations involving a series of consecutive processes must form immediate premises (APo II 12, 95b13-15; cf. APo II 12, 95b24-5). Aristotle's explanation of this requirement is somewhat obscure, but he seems to say that in a given causal chain in which cause and effect occur consecutively and not simultaneously (e.g., the occurrence of $\mathrm{A}$ at $t_{1}$ causes occurrence of $\mathrm{C}$ at $t_{2}$, and then $\mathrm{C}$ causes the occurrence of $\mathrm{D}$ at $t_{3}$ ), we can find the explanatory middle term by drawing inferences from what occurs later to what necessarily had to occur earlier. The starting point of such inferences is always the later event, which is the closest to the present, and from there we are supposed to work our way back to the necessary prerequisites of this later process that we know has come about. In other words, Aristotle states that we can infer the (earlier) occurrence of A from the (later) occurrence of D through C: given that A is an immediately necessary precondition for the occurrence of $C$, and $C$ is immediately necessary for $D$, we are allowed to draw the inference that if $\mathrm{D}$ has come about A must have come about (earlier), and that the cause is $C$ ( $A P o$ II $12,95 \mathrm{~b} 19-20)$. Aristotle illustrates this with a concrete example (APo II 12, 95b31-7):

And it is this way with regard to concrete things: if a house has come to be, it is necessary that stones have been cut and have come to be (ei gegonen oikia, anagkê tetmêsthai lithous kai gegonenai). Why is this? Because it is necessary that a foundation has come to be, if also a house has come to be. If a foundation, then it is necessary that earlier stones have come to be. Again, if there will be a house, in the same way there will have to be stones earlier. And it is similarly brought out through the middle term: for there will be a foundation earlier (estai gar themelios proteron).

From the coming to be of a house (which is what has come to be later and is closest to the present, and forms therefore the starting point of the inference), we can infer the necessity of stones having come to be earlier, because a foundation is a necessary condition for the coming to be of a house, and stones are a necessary condition for the coming to be of a foundation. The earlier occurrence of stones is thus brought out through the middle term, which is the earlier presence of a foundation. 
Again, it does not make a difference whether the inference pertains to the past, present, or future: as long as the middle term is homogenous to the extremes, the inference is valid. (I take it that this example illustrates the mode of inference that is appropriate with regard to consecutive causal chains and not necessarily a demonstration itself.)

Taking these three points together, it appears that Aristotle in this section characterizes demonstrations concerning linear sequences of (same-type) causes and effects as involving one-directional inferences from the chronologically posterior to the prior, in which the necessity of the occurrence of the prior is derived from the occurrence of the posterior. The middle term in such demonstrations ought to pick out a cause that constitutes an immediately necessary prerequisite for the effect (i.e., the coming to hold of an attribute of a subject) that has come about.

This characterization of the second model of demonstration is important for the following three reasons. First, it shows that Aristotle at least had a modal notion of conditional necessity ${ }^{30}$ when he wrote the Posterior Analytics. Second, I believe that the characterization of this second model provides the conceptual foundations for the model of demonstration in the natural sciences that Aristotle develops in Parts of Animals Book I, for demonstrations of the natural kind follow the same inference scheme. The innovation of the account in the Parts of Animals is that Aristotle provides a teleological interpretation of the consecutive causal chain, which was absent in the Posterior Analytics. Third, it explains Aristotle's methodological preoccupation with determining what process or development comes to be before what in natural causal sequences. Here it appears that Aristotle uses chronological priority as a way to detect causal priority - a method that surfaces in a couple of passages in Parts of Animals Books I-II, but which is particularly prominent in Generation of Animals Book II. In the sections below, I shall specify each of these claims.

Aristotle's modal notion of conditional necessity

Let me start with my first claim that Aristotle's discussion of demonstrations of same-type processes in APo II 12 shows that he had already

30 On Aristotle's modal use of necessity and its possible presence in the Posterior Analytics, see Kupreeva (forthcoming). 
developed a modal notion of conditional necessity in the Posterior Analytics (perhaps before developing a causal one). Traditionally, scholars have contested precisely this claim, ${ }^{31}$ but I believe that they do so only because they do not distinguish between what Kupreeva calls a modal and a causal use of Aristotle's notion of necessity.

Usually, and especially when discussing the types of causes operative in nature, Aristotle refers to necessity to indicate a particular type of causality. This is the causal use of necessity: it refers to the necessity of materials acting to their own material nature in a way that is either dependent or independent of some pre-existing internal potential for form that needs to be realized (i.e. conditional versus material necessity). For instance, in Ph II 9, 199b34-200a15, Aristotle explicates how necessity operates in natural things that are for the sake of something ${ }^{32}$ and concludes, without rejecting the necessity of material natures altogether, that in natural generation, the necessity that is operative is not unqualified, material necessity as his predecessors had thought, but rather conditional necessity (Ph II 9, 200a13: ex hupotheseôs de to anagkaion).

In other contexts, however, and in particular when discussing the type of demonstration required in the natural sciences as opposed to that required in the other theoretical sciences (such as in PA I 1, 639b2940a9, Ph II 9, 200a15-30, and GC II 11, 337b14-25), Aristotle uses necessity to refer to a particular type of modal relationship that holds between two either consecutive or simultaneous states of affairs in a continuous causal sequence. This is what Kupreeva has termed the modal use of necessity: $:^{33}$ it is concerned with the nature of causal inferences and with the question of whether the cause necessitates its effect always and necessarily, or only for the most part and contingently (i.e. unqualified necessity versus material or conditional necessity).

Let me give a concrete example of these uses. Suppose (as we did in APo II 12,95a16-21) that ice is the solidification of water due to a

31 See e.g., Lennox (2001a), xxii and 102.

32 Cf. Ph II 8, 198b11-12: epeita peri tou anagkaiou, pôs echei en tois phusikois. See Cooper (1987), 262.

33 Note that Kupreeva's observation that Aristotle sometimes uses (his familiar notions of) necessity in a modal way (i.e. in order to identify the type of necessity that obtains between cause and effect in linear causal sequences) does not require us to attribute a (contemporary) notion of 'modal necessity' to Aristotle, which is a move I would resist. 
complete cessation of heat. For the natural scientist, there are (at least) two questions here that are relevant and proper to his science. First, we need to establish whether the phenomenon of ice-formation is due to teleology or rather to material necessity. The answer to this question will identify the nature of the causality that underlies processes of ice-formation. Here the answer is 'material necessity', used in a causal sense. Second, and this question is particularly important if we want to provide demonstrations of why ice comes about and get the causal inference right, we need to establish whether, when there is a complete cessation of heat, we can be sure that there will always, without exception, be a solidification of water. In other words, is it the case that the relation between 'complete cessation of heat' and 'solidification of water' is necessary in an unqualified way, or is it rather necessary in a qualified way? If the relation is one of unqualified necessity, we can infer the presence of the effect from the current presence of the cause (for the cause will always, without exception, necessitate its effect). If the relation is one of necessity in a qualified way, then we cannot draw any causal inference from cause to effect (for it is not absolutely necessary that when the cause occurs, the effect occurs as well), but only from effect to cause (given that the effect has occurred, it is absolutely necessary that the cause has occurred as well). Here the answer seems to be that the relation between cause and effect is not one of unqualified necessity (as we shall see shortly, sublunary natural processes that are non-cyclical never involve relations of unqualified necessity), but rather one of material necessity in a modal sense.

Now, it is clear that in APo II 12 Aristotle is not particularly interested in identifying the mode of causality that is, for instance, responsible for the coming to be of a house. He nowhere qualifies the sequence from stones to foundations to a house as teleological, although I take it that Aristotle usually takes this sequence to be a proper and paradigmatic case of an (artificial) teleological causal chain (cf. Ph II 9, 200a24-9; PA II 1, 646a27-8; and PA III 5, 668a13-24). His main concern is with specifying what kind of causal inferences we are allowed to draw in cases where $A$ is the cause of $B$, but where $B$ does not occur at the same time as $\mathrm{A}$ but instead occurs later. His answer is that the inference is to start with what happens later: the prior occurrence of $A$ can be said to be necessary, given the later occurrence of $B$ and $A$ being a necessary prerequisite for B. Aristotle gives a similar account of the direction causal inferences can take depending on whether the necessity involved in such sequences is 'conditional' or 'unqualified' in On Generation and Corruption book II (GC II 11, 337b14-25): 
If it is the case that the coming to be of something earlier is necessary if a later thing is to be (ei dê to proteron anagkê genesthai, ei to husteron estai), e.g., if a house, then foundations, and if that [i.e., foundations], then clay, does it follow that if there have come to be foundations a house, too, must necessarily come to be? Or can we not yet say this, unless it is necessary without qualification (anagkê haplôs) that the latter itself come to be? If that is the case, then it is necessary that also the house comes to be when the foundation has come to be: for such was the relation of the earlier to the later, namely that if that one is to be, necessarily the other one will be first. If, accordingly, it is necessary for the later one to come to be, it is necessary also for the earlier one; and if the earlier one comes to be, it is accordingly necessary for the later one [to come to be too] - but not because of the earlier one, but because it was assumed that it was necessary that it would exist. So in those cases where it is necessary for the later one to exist, there is conversion, and it is always necessary, if the earlier has come to be, that the later should also come to be.

The example Aristotle uses to illustrate two kinds of causal inferences, one starting from the prior, the other from the posterior, is the same as in APo II 12: the coming to be of the prior (i.e., the foundations) is necessary if the posterior (i.e., the house) is to be, but it is not the case that once the prior has come to be, the posterior will necessarily come to be as well (i.e., the presence of foundations does not guarantee the presence of the house). Only if the necessity between the processes in a process of coming to be is absolute, for instance, when we posit that the relationship between foundations and a house is necessary 'without qualification', would the causal inference 'if there are foundations, the house will be as well' be valid. As Aristotle points out, only in the latter cases does the inference convert.

Following the On Generation and Corruption Book II passage quoted above, Aristotle links these different types of causal inferences to the different types of processes that occur in the natural world: absolutely necessary relations between the prior and the posterior hold only of things that are eternal and/or are subjected to eternal cyclical processes (such as the movement of the heavens, the evaporation-cycle, and the cycle of air; see GC II 11, 337b30-8a18), whereas conditionally necessary relations pertain to the generation of animals, which is a sublunary natural process that is rectilinear and that concerns beings whose substances are perishable (GC II 11, 338b6-11; GC II 11, 338b9-11: 'For it is not necessary if your father came to be, that you come to be, but 
if you came to be, then he came to be'). In short, for natural processes that are linear and not eternal the prior in a consecutive causal chain necessitates the posterior only for the most part (by whatever type of causality), which means that the necessity between those two processes is never unqualified and does not convert (i.e., only if $B$, then necessarily A). Again, Aristotle is not concerned here with identifying the type of causality that is operative in various kinds of natural processes ${ }^{34}$ but only with the type of necessity that holds between the prior and the posterior in such causal chains, regardless of whether the posterior is the end that constitutes the final cause of that process or just any later event within a causal sequence.

In sum, the modal notion of conditional necessity employed in GC II 11 and APo II 12 is the same. What the account in GC II 11 adds to the picture is how this model of inferences translates to the explanation of actual natural processes that are linear and non-eternal, but without yet specifying the causal 'color' of the causal chain at stake. An explicit teleological interpretation of this causal chain is offered only where Aristotle differentiates the various causal powers at work in nature, such as for instance in Physics book II (specifically: in Ph II 9, 199b34-200a30; 200a24-29):

Such that if there will be a house, it is necessary that these things come to be or are present or exist (hôst' ei estai oikia, anagkê tauta genesthai $\hat{e}$ huparchein), or in general the matter that is for the sake of something, such as bricks and stones, if it is a house. However, it is not because of these that there is an end, except as the matter, nor will it be because of these. However, in general without these things being present there will not be a house or a saw, in the first case if there are no stones, in the second if there is no iron. (Cf. PA I 1, 640a4-5 and 642a7-12).

In this passage, Aristotle takes the outcome of a consecutive causal chain to be the end and final cause of that whole process, and qualifies the preceding stages as conditionally necessary prerequisites that have to be present first (and be changed in certain ways) if the end is to be re-

34 Cf. Lennox (2001a), 138 about GC II 11, 338b11-12: 'The argument is formulated in the language of 'hypothetical' necessity, but it is not an example which illustrates hypothetical necessity at all.' Under my interpretation, Aristotle is talking about conditional necessity in a modal sense here, and not - as Lennox points out - about conditional necessity in a causal sense. 


\section{Mariska Leunissen}

alized. This is the causal notion of conditional necessity, which is indeed absent from the Posterior Analytics, but which is conceptually consistent with its modal counterpart that Aristotle analyzes in APo II 12.

The second model of APo II 12 as a blueprint for Aristotle's

model of demonstration in the natural sciences

I submit that Aristotle's analysis of demonstrations involving causal chains in which the cause and effect do not occur simultaneously in APo II 12 forms the immediate model for what demonstrations in the natural sciences should look like. ${ }^{35}$

The crucial text in the Parts of Animals is the following (PA I 1, 639b2940a9):

However, the mode of demonstration and of necessity is different (ho tropos tês apodeixeôs kai tês anagkês heteros) in the natural and the theoretical sciences. These have been discussed elsewhere. For the starting point is in some [i.e., the theoretical sciences] what is, but in others [i.e., the natural sciences] what will be. For: 'since health or man is such, it is necessary that this is or comes to be' (epei gar toionde estin hê hugieia ê ho anthrôpos, anagkê tod' einai ê genesthai), but not 'since this is or has come to be, that of necessity is or will be.' Nor is it possible to connect the necessity in such a demonstration to eternity, so as to say, 'since this is, therefore that is'. These matters too have been determined elsewhere, namely in what sorts of things [this kind of necessity] is present, what kind of processes convert and because of what cause.

The distinction Aristotle explicates between demonstrations in the natural sciences (i.e., those that pertain to generated natural things) ${ }^{36}$ and

Pace Lloyd (1996), 32.

36 This divide between the natural sciences that are concerned with generation and the [other] theoretical sciences that are concerned with eternal, non-generated things is created in the preceding passage (PA I 1, 639b22-2). In this passage, Aristotle differentiates the domains of the natural world according to the type of necessity that pertains to it, and thereby introduces a special type of necessity into the domain of generated natural beings. While unqualified necessity holds of the eternal, natural realm of the heavenly bodies, among the generated natural beings there is also a kind of necessity present, namely conditional necessity (this is what 
demonstrations in the theoretical sciences pertains, first, to the direction of the inference, and, second, to the modal type of necessity picked out in the demonstration. Since (teleological) demonstrations in the natural sciences pertain to causal sequences in which cause and effect are separated in time, and since 'we cannot connect the necessity in such a demonstration to eternity' (which means that Aristotle must be excluding the heavenly and circular natural phenomena here), we can only draw inferences from what has already come to be to its antecedent causes. The starting point for demonstrations in the natural sciences ${ }^{37}$ is thus the posterior, which is usually the realized end, from which its necessary antecedents can be deduced: the inference in natural demonstrations is one-directional from end to the preconditions of the end, and the necessity picked out in such teleological demonstrations is conditional necessity (cf. Aristotle's example of such a demonstration in $P A$ I 1, 642a32-b2). For the objects of the theoretical sciences, on the other hand, which do not involve generation, the starting point of the inference is the prior, from which one can derive the posterior, because the relation between the two is absolutely necessary or necessary 'in an unqualified way'.

In other words, I believe that the only addition Aristotle makes in the Parts of Animals to his model of demonstration involving sequences of same-type causes and effects that he developed in APo II 12 is a teleological interpretation of this causal sequence: since demonstrations in the natural sciences by definition apply to natural phenomena, and since natural phenomena are (at least for the most part) teleological, the causal sequences at stake are (again, at least for the most part) going to be teleological. The end that constitutes the final cause becomes the starting point of the demonstration, and the middle term will have to

I take to be the most natural reading of the particle kai in PA I 1, 639b23). See also Lennox (2001b), 128-9.

37 Normally, Aristotle depicts natural science as being itself one of the theoretical sciences (see Lennox 2001b, 129; Metaph E 1, 1025b18-6a23 and PA I 1, 641b11), and distinguishes the theoretical sciences from the practical and productive ones. In this passage, however, Aristotle singles out that part of the science of being that is concerned with generated things from that which is concerned with eternal things. I believe that this reading is most consistent with the preceding distinctions between the natural generated beings on the one hand and the eternal (natural) beings on the other. Natural science thus has to be understood in the narrow sense of the science that deals with natural beings whose substances are perishable. For alternative interpretations, see Lloyd (1996), 29, and Johnson (2005), 162-3. 
pick out the conditionally necessary antecedents. The mode of inference itself, however, remains the same as the one outlined in APo II 12 (i.e., backwards from the posterior to the prior), since this mode applies to all causal chains in which cause and effect come to be consecutively in a non-circular way.

Chronological order as a means to track causal order in the biological works

Third, since many if not most sublunary natural phenomena and their properties come to be as a result of linear teleological developments, demonstrations of their coming to be face the extra challenge of not only picking out the primary causal factor through the middle term, but also of specifying the actual sequence and the timing of the processes to be picked out in the demonstrative syllogism. ${ }^{38}$ In fact, as Aristotle indicates in APo II 12, it is only through reconstructing the exact order of processes that we are able to identify the primary causal factor and the immediate premises (involving causal per se relations) from which demonstrations of processes could possibly be constructed. ${ }^{39}$

This concern for specifying the order and timing of natural processes for the sake of providing (teleological) explanations of these processes is also evidenced in Aristotle's biological works: in his Parts of Animals, Aristotle specifies what he means by 'order in generation' and how it relates to 'order in being', and in his Generation of Animals, he appears both to literally follow this 'order in generation' at the level of exposition and to explicitly use order in generation as a means to identify different kinds of causal roles.

The most explicit discussion of what Aristotle means by 'order in generation' occurs in PA II 1. There Aristotle lays out the three different kinds of composition from which all animals and their parts are constituted. The first constitution consists of the four elements (or perhaps more specifically their material potentials), the second consists of the uniform parts, and the third and last consists of the non-uniform parts. The ordering appears to be chronological, following the actual

38 Cf. Gotthelf (1987), 237-8. See perhaps also: $P h$ II 7, 198a34-5): 'For with regard to generation it is mostly in this way that people investigate into the explanations - 'what comes to be after what?', and 'what was the first to act or to undergo?', and in this way at each step of the series.'

39 Cf. Charles (2000), 198-204. 
order of coming to be, for Aristotle immediately points out that 'order in generation' is the opposite from 'order in substantial being' or 'order in nature' (PA II 1, 646a24-b2). Whereas order in being is explained to pertain to priority relations in nature and in definition, the order in generation is depicted as a chronological order (PA II 1, 646a35: tôi chronôi) that tracks what comes to be from what origin and into what end, thus revealing the efficient and final causes of the natural, teleological process (PA II $1,646 a 30-5):^{40}$

For each thing that comes into being is generated from something and into something, namely from an origin to an origin, from a first mover and what already has some nature to some shape or whatever other end: for a human being generates a human being, and a plant a plant, from the underlying matter of each.

From this Aristotle concludes that matter and generation are necessarily prior in time, but that substantial being and shape are prior in definition. In his application of these distinctions to his analysis of the three material compositions, Aristotle then seems to suggest that the observed chronological order of the generation of parts can be used as an indication (but not necessarily anything stronger than that) of the causal relation between parts (PA II 1, 646b5-10):

Such that the matter of the elements is necessarily for the sake of the uniform parts (hôste tên men tôn stoicheiôn hulên anagkaion einai tôn homoiomerôn heneken). For the latter are later in generation than the for-

40 This distinction builds on Aristotle's earlier discussion of the relation between generation and being in PA I 1, 640a10-b4. There he argued that the chronological order of the coming to be of the parts of an animal ought always to be explained by reference to the being of that animal, because generation is for the sake of being, and not the other way around, as Empedocles thought.

Aristotle points to two factors that ensure this teleological relation between generation and being: first, the potential for form that is already present in the seed at the very beginning of the development, and second, the producer who is prior - not only in definition, but also in time - to the product. In other words, the process of sexual reproduction, which is a paradigmatic case of natural teleology, starts (in a chronological sense) with the presence of a producer who already possesses the form in a realized form, who then by means of his seed transmits a potential for the realization of the same form into the female menses; the process ends in time with the completed realization of the form, which constitutes the animal's final cause, and which is prior in definition and in nature. 
mer, and the non-uniform parts [are later in generation than] them [i.e., the uniform parts]: for those [i.e., the non-uniform parts] already have the end and the limit, having received a constitution of the third number, just as often happens when generations are completed.

In this passage, Aristotle applies his earlier suggestion (made in PA II $1,646 \mathrm{a} 25-6$ ) about the correlation between being last in generation and being first in nature: since the non-uniform parts are the last to come to be, one may conclude (I take this to be the force of the hôste in PA II $1,646 \mathrm{~b} 5)$ that they are that for the sake of which the elements and the uniform parts come to be. ${ }^{41}$

In the Generation of Animals, Aristotle follows this 'order of generation' as an ordering principle of his discussion of (the parts and efficient causes of) animal reproduction (cf. GA I 2, 716a2-4; GA II 1, 733a32-3; and GA IV 8, 776b3-4). Schematically, the account starts by identifying the first principles of sexual generation, i.e., the male and the female (GA I 1-2); then it discusses the reproductive organs (GA I 3-23); gives a causal explanation of embryological development (GA II-III); explains the mechanisms of sexual differentiation and heredity (GA IV 1-3); discusses phenomena surrounding birth (GA IV 4-10); and finally discusses those differences of the more and the less that arise in animal parts in the later development of the animal, after its birth (Generation of Animals V). Aristotle's account thus tracks animal generation from its first efficient causes to the attributes of the fully developed animal.

However, it is in Aristotle's discussion of embryogenesis in Generation of Animals Book II that his concern for detecting the right order of processes in generation is most apparent. The first few chapters deal with the question of whether it is the heart that is the source of the other

41 I am tempted to read Aristotle's initial analysis of the city in the Politics as a similar application of this 'methodological principle' of laying out the chronological order of the coming to be of parts in order to detect the causal relations between them. For, in Pol I 1, Aristotle proposes that, in order to determine in what ways different kinds of rule differ from one another, one ought to analyze the whole city into its basic elements ( $P o l$ I 1, 1252a18-23), but then carries out this constitutive analysis in Pol I 2 by a quasi-etiological account ( $\mathrm{Pol} \mathrm{I} 2,1252 \mathrm{a} 24-6)$ of how the city developed naturally out of simpler communities and of how this city constitutes their natural end. Again, the suggestion is that the genetic account (whether or not it is to be taken literally) gives us a clearer and better view of the subject under investigation ( $\mathrm{Pol}$ I 2, 1252a24-6). 
parts of animals, and if so, whether it generates them simultaneously or in succession (GA II 1, 734a16-22):

Concerning the other parts - how [does the heart make those]? For either all parts, such as the heart, lung, liver, eye, and each of the other ones, come to be simultaneously (hama), or [they come to be] in succession (ephexês), just as in the words ascribed to Orpheus: for there he said that a living being comes to be in the same way as the weaving of a net. That they [do] not [come to be] at the same time is clear also to perception: for some of the parts seem already to be present in there, whereas others do not.

In this passage, Aristotle tries to determine whether - in the language familiar from the Posterior Analytics - the process of the generation of animal parts is a simultaneous or a consecutive causal chain. Empirical evidence speaks in favor of the latter, and Aristotle concludes that parts come into being one after another (GA II 1, 734a25: tode meta tode; GA II 1, 734a25-33). In the later chapters, he argues that the generation of the heart, which is the first principle of growth of the animal (GA II 4, 740b2-4; cf. PA III 4, 666a18-21), is followed by the formation of first the internal and then the external parts (GA II 4, 739b34-40a23; GA II 6, 741a25-6).

In GA II 6, Aristotle lays out a detailed method for determining the order in which the parts of animals develop, which cannot always be observed (bigger parts often appear earlier even though they started developing later: GA II 6,741b26-7) and is something that 'is not easy' to determine (GA II 6, 742b6-7 and GA II 6, 742b9-10). Criticizing some of the ancient natural philosophers for not being experienced enough with this matter, Aristotle again points out that there are differences in priority in generation and in substantial being (GA II 6, 742a16-25):

Some of the ancient natural philosophers tried to say which part comes into being after which ( $t i$ meta ti gignetai tôn moriôn), but they were not too experienced with what happens. For among the parts, just as with regard to other things, one naturally comes to be prior to the other. But 'prior' is said in many ways: for 'that for the sake of which' and 'that which is for the sake of something' are different, and while of the two the latter is prior in generation (to men têi genesei proteron), the former [is prior] in substantial being (to de têi ousiai). And that which is for the sake of something' also admits of two differences: for the one is the origin of movement and the other is that which 'that for the sake 
of which' makes use of. I mean for instance that which produces and that which is instrumental to the producer.

In conformity with his discussion of priority-relations in the Parts of Animals, Aristotle here identifies the end (which constitutes the final cause of something) as being prior in definition, whereas that which is for the sake of the end (at least in the sense of that which is the source or the producer of the end) as being prior in generation. Based on this distinction, Aristotle then continues to identify three types of biological parts whose place in the order of coming to be is tied closely to their causal role. First, there are parts that are a source of other parts: they are the principle of motion and generation and therefore necessarily have to come to be first. Second, there are parts that are 'that for the sake of which' and that make use of other parts: they come to be after the first type of parts has come into being. Finally, there are parts that are for the sake of something and are used by other parts (Aristotle calls these parts 'instrumental'): these parts come to be last (GA II 6, 742a16-b18).

The underlying teleological idea of this three-fold division in the chronology of the coming to be of parts is that nature does not produce parts before the animal is actually able to use them (otherwise, these parts would be in vain; see the analogy with the flute-player in GA II 6, 742a26-8), conjoined with the fact that parts that are of the nature of an origin necessarily come to be first. With this method in hand (GA II 742b10-11: kaitoi kata tautên methodon dei zêtein ti gignetai meta ti), Aristotle is now able to state that the heart comes to be first (as it is the principle of motion) ${ }^{42}$ then the upper half of the body, and finally the lower parts (GA II 6, 742a36-b18; with the formation of the eye being the only observed anomaly: GA II 6, 743b32-4b11). In the remainder of GA II 6, Aristotle further specifies this picture, while being careful to distinguish source from end, and instrumental parts from parts that are themselves an end. ${ }^{43}$

42 Cf. GA II 6, 742b33-3a1: 'for the starting point in things that are without motion is the "what it is", in things that come to be there are several [starting points] — different in mode and not all the same - one of which is the origin of motion. And therefore all blooded beings receive a heart first, as was said in the beginning; in the other beings the analogue to the heart comes to be first.'

43 In short, the picture is as follows: from the heart the bloodvessels grow and extend throughout the body; from these bloodvessels the other parts grow, starting with the upper half of the body (with the brain growing first; next the eyes, which, 
What this discussion in GA II 6 illustrates is that the order of a part in generation is closely related to and in part even determined by its causal role within the development of the animal: sources of growth and motion, which constitute efficient causes, are prior in generation; ends produced by those sources, which constitute final causes, are prior in definition, but last in generation. Things produced by those sources and used by the ends, are themselves ends only in a secondary sense: although they are the very last to come to be, they are not prior in definition. Sorting out the order of consecutive processes within a development helps sorting out the causal relations between those processes (and vice versa), and knowledge of these causal relations is a necessary condition for the construction of scientific demonstrations.

In sum, even though Aristotle never provides any full-fledged syllogistic demonstrations in his biological works, it seems that at least the mode of inference and the concern for tracking order in generation are driven by his analysis of demonstrations of same type processes in APo II 12.

\section{Conclusion}

In this paper I have sought to show how Aristotle in both his theory and practice of the biological sciences is influenced by the two models of demonstration of processes outlined in APo II 12.

The first model pertains to causes and effects that come about simultaneously and seems particularly fit for the incorporation of natural processes that are entirely due to material-efficient causation. The examples of demonstrations of the coming to be of eclipses and of ice are formally the same as many of the explanations of the coming to be of 'attributes by which parts of animals differ' discussed in Generation of Animals Book V, except, of course, that the latter are never actually presented in a formalized manner. The second model pertains to causes and effects that come to be consecutively in a linear causal chain and that are of the same type, i.e., that are all past, present, or future happenings. This model appears to be particularly well suited for the incor-

however, do not come to completion until the very end of the embryogenesis), then the other necessary parts (which coincide with the second category of parts mentioned above), and finally the instrumental parts (which coincide with the thrid category of parts mentioned above). 
poration of teleological processes in scientific demonstrations: both the mode of inference involved (i.e., reasoning backwards from the actual end result to its conditionally necessary antecedents) and the depiction of the middle term as picking out the immediately necessary antecedent of the effect (i.e., some end holding of some subject) are similar to Aristotle's characterization of the mode of demonstration that is special to the natural sciences in Parts of Animals Book I. In addition, Aristotle's efforts to determine the chronological order of the coming to be of parts of animals in PA II 1 and GA II 6 seem to be influenced by his concern for discovering immediate premises as expressed in APo II 12.

None of my claims in this paper come close to settling the question of the relationship between Aristotle's scientific theory and practice, but at least I hope to have shown that the account of demonstration in the Posterior Analytics is richer than has often been assumed and that it already contains the seeds for a more developed account of demonstration in the natural sciences as is presented in Parts of Animals Book I. Aristotle does not present a monolithic, purely geometric-style model of demonstration in the Posterior Analytics, but from the beginning he opens up the possibility that there are demonstrations of processes with their own mode of inference, necessity, and syllogistic structure.

\section{List of references}

Balme, D.M. 1987. 'Aristotle's Use of Division and Differentiae'. In A. Gotthelf and J.G. Lennox, eds., Philosophical Issues in Aristotle's biology, 69-89 (New York: Cambridge University Press).

Barnes, Jonathan. 1993. Aristotle: Posterior Analytics, 2nd edn. (Oxford: Clarendon Press).

Bolton, R. 1987. 'Definition and Scientific Method in Aristotle's Posterior Analytics and Generation of Animals'. In A. Gotthelf and J.G. Lennox, eds., Philosophical Issues in Aristotle's Biology, 120-66 (New York: Cambridge University Press).

. 1997. 'The Material Cause: Matter and Explanation in Aristotle's Natural Science'. In W. Kullmann and S. Föllinger, eds., Aristotelische Biologie: Intentionen, Methoden, Ergebnisse, 97-124 (Stuttgart: Franz Steiner Verlag).

Charles, David. 1997. 'Aristotle and the Unity and Essence of Biological Kinds'. In W. Kullmann and S. Föllinger, eds., Aristotelische Biologie: Intentionen, Methoden, Ergebnisse, 27-42 (Stuttgart: Franz Steiner Verlag). 
1999. 'Aristotle on Substance, Essence and Biological Kinds'. In Lloyd P. Gerson, ed., Aristotle: Critical Assessments Vol. 2, 227-255 (London: Routledge).

Cooper, J.M. 1987. 'Hypothetical Necessity and Natural Teleology'. In A. Gotthelf and J.G. Lennox, eds., Philosophical Issues in Aristotle's Biology, 243-274 (New York: Cambridge University Press).

Detel, W. 1997. 'Why all Animals have a Stomach. Demonstration and Axiomatization in Aristotle's Parts of Animals'. In W. Kullmann and S. Föllinger, eds., Aristotelische Biologie: Intentionen, Methoden, Ergebnisse, 63-84 (Stuttgart: Franz Steiner Verlag).

1999. 'Aristotle on Zoological Explanation', Philosophical Topics 25: 43-68.

Ferejohn, Michael. 1990. The Origins of Aristotelian Science (New Haven, CT: Yale University Press).

Gotthelf, Allan. 1976-77. 'Aristotle's Conception of Final Causality'. Review of Metaphysics 30: 226-54. Reprinted with additional notes and a postscript in A. Gotthelf and J.G. Lennox, eds., Philosophical Issues in Aristotle's Biology, 204-242 (New York: Cambridge University Press).

. 1987. 'First Principles in Aristotle's Parts of Animals'. In A. Gotthelf and J.G. Lennox, eds., Philosophical Issues in Aristotle's Biology, 167-198 (New York: Cambridge University Press).

1997. 'The Elephant's Nose: Further Reflections on the Axiomatic Structure of Biological Explanations in Aristotle'. In W. Kullmann and S. Föllinger, eds., Aristotelische Biologie: Intentionen, Methoden, Ergebnisse, 85-95 (Stuttgart: Franz Steiner Verlag).

Johnson, Monte Ransome. 2005. Aristotle on Teleology (Oxford: Oxford University Press).

Kupreeva, I. forthcoming. 'Causation and Conditional Necessity in Posterior Analytics II 12'. In F.A.J. de Haas and M.E.M.P.J. Leunissen, eds., Interpreting Aristotle's Posterior Analytics in Late Antiquity and the Byzantine Period (Leiden: Brill).

Lennox, James G. 2001a. Aristotle's Philosophy of Biology, Studies in the Origins of Life Science (Cambridge: Cambridge University Press).

2001b. Aristotle: On the Parts of Animals I-IV. Translation with notes (Oxford: Oxford University Press).

Leunissen, M.E.M.P.J. 2007. 'The Structure of Teleological Explanations in Aristotle: Theory and Practice'. Oxford Studies in Ancient Philosophy 33: 145-78.

Leunissen, Mariska and Allan Gotthelf. In preparation. 'What's Teleology got to do with it? A Reinterpretation of Aristotle's Generation of Animals V'.

Lloyd, G.E.R. 1996. 'The Theories and Practices of Demonstration'. In G.E.R. Lloyd, Aristotelian Explorations, 7-37 (Cambridge: Cambridge University Press).

Mendell, H. 1998. 'Making Sense of Aristotelian Demonstration'. Oxford Studies in Ancient Philosophy 16: 160-225.

2004. 'Aristotle and Mathematics'. In Edward N. Zalta, ed., Stanford Encyclopedia of Philosophy, URL = http://plato.stanford.edu/entries/aristotle-mathematics/ 


\section{Mariska Leunissen}

Pellegrin, P. 1986. Aristotle's Classification of Animals: Biology and the Conceptual Unity of the Aristotelian Corpus. Trans. A. Preuss (Berkeley: University of California Press).

Verdenius, W.J. 1981. 'Notes on Some Passages in Book I'. In Enrico Berti, ed., Aristotle on Science: The Posterior Analytics (Padua: Antenore).

Wieland, W. 1975. 'The Problem of Teleology'. In J. Barnes, M. Schofield, and R. Sorabji, eds., Articles on Aristotle. Volume 1: Science, 141-60 (London: Duckworth). 